\title{
EDITORIAL
}

\section{Implications of the growing obesity epidemic on contraception and reproductive health}

\begin{abstract}
Background
There is an obesity epidemic hitting all developed countries. This is having a huge impact on health, with the direct cost of obesity to the National Health Service recently quoted as $£ 0.5$ billion. The indirect costs are even higher, being estimated at about $£ 2$ billion. Prevalence rates in developed countries have now reached record levels, with more than $25 \%$ of people in the USA and $20 \%$ in Australia being obese. In the UK $22 \%$ of men and $24 \%$ of women are obese. ${ }^{1}$

Why are we getting fatter? We are now expending less energy in daily life but are eating high calorific junk food. We are a nation of car owners - in days gone by children used to walk to school and adults to work. Worryingly, $8.5 \%$ of 6 -year-olds and $15 \%$ of 15 -year-olds are clinically obese. This is storing up health problems for the future with obesity being an independent risk factor for type 2 diabetes and cardiovascular disease.
\end{abstract}

\section{Effects on fertility and pregnancy}

There is some evidence to suggest that obesity may affect fertility. Most studies investigating this area have included overweight women with ovulatory dysfunction, which will bias results. A European study, however, looked at the effect of body mass index (BMI) on delayed conception (9.5 months of unprotected sexual intercourse) by using a population-based survey of pregnant women. In smokers there was a strong association between obesity (BMI $\geq 30$ $\mathrm{kg} / \mathrm{m}^{2}$ ) and delayed conception [odds ratio $(\mathrm{OR})=11.54$ 95\% confidence interval (CI) 3.68-36.15]. This association was not found in non-smokers. ${ }^{2}$ Leptin is a protein hormone, secreted by adipocytes, which may have effects on the hypothalamic-pituitary axis and sex hormone levels. Circulating levels of leptin may provide the link between BMI and fecundity. In those who are overweight, increased leptin production results in appetite suppression and supposed weight loss but in the obese there appears to be 'leptin resistance'. Smokers have lower levels of leptin, and the combination of being obese and smoking may also affect leptin levels. ${ }^{2}$

Excessive pre-pregnancy weight is also associated with adverse pregnancy and perinatal outcomes through increasing hypertensive diseases (chronic hypertension and pre-eclampsia), diabetes (pre-pregnancy and gestational), rates of Caesarean section and infections. Obesity is associated with a higher rate of venous thromboembolism (VTE) and respiratory complications in pregnancy, and may be an independent risk factor for neural tube defects in infants and fetal mortality. Maternal obesity increases the risk of delivering a large-for-gestational-age neonate, which in turn increases the risk of subsequent childhood obesity. ${ }^{3}$

One study showed that compared to women weighing $100-149 \mathrm{lb}(45-67 \mathrm{~kg})$, women over $300 \mathrm{lb}(>136 \mathrm{~kg})$ had a five-fold increased risk of gestational diabetes and preeclampsia with almost a three-fold increased risk of Caesarean section. These women were also four times more likely to have a macrosomic infant, and infants were twice as likely to be treated in a neonatal intensive care unit even when mothers with diabetes and hypertension were excluded. ${ }^{4}$ A further study investigating more than 280000 women in London, UK showed that maternal obesity carries significant risks for the mother and baby, with the risk increasing with the degree of obesity and persisting after accounting for other confounding demographic variables. ${ }^{5}$ Table 1 shows a summary of the results from this study.

Polycystic ovary syndrome (PCOS) is characterised by anovulation, infertility and hyperandrogenism, with clinical manifestations of irregular menstrual cycles, hirsutism and acne. The condition affects an estimated $5-10 \%$ of women of reproductive age 6 in the UK, with the highest prevalence reported in the South Asian community. A recent study suggested that $52 \%$ of this population had PCOS, with $49 \%$ having associated menstrual irregularities. ${ }^{7}$ It is not surprising that the prevalence of PCOS appears to be increasing in line with the current obesity epidemic. In women with PCOS, obesity worsens both their symptomatology and endocrine profile. Weight loss in sufferers with BMI $>30 \mathrm{~kg} / \mathrm{m}^{2}$ improves these factors and the likelihood of ovulation and pregnancy. ${ }^{8}$

\section{Obesity and contraception}

Here there are three areas of importance. Is there evidence of weight gain associated with the contraceptive method? Does BMI impact on that product's contraceptive efficacy? Will an increase in BMI affect the safety profile of the method?

\section{Combined oral contraceptives}

Many women blame their oral contraceptive when they put on weight. A recent Cochrane Review identified three placebo-controlled, randomised trials and could not find evidence supporting a causal association between combined oral contraception (COC) and weight gain. ${ }^{9}$ Initial data for combined hormonal patches also suggest no association with weight gain. ${ }^{10}$

What is the impact of prescribing a combined hormonal contraceptive to overweight women? Data suggest that obesity alone increases the risk of VTE and cardiovascular disease. Recent studies ${ }^{11,12}$ looking at COC users have shown a two- to five-fold increase in VTE risk in women with a BMI $>30 \mathrm{~kg} / \mathrm{m}^{2}$, while these and others ${ }^{12,13}$ suggest two- to six-fold increases in women with a BMI $>25 \mathrm{~kg} / \mathrm{m}^{2}$. In a case-control study from the Netherlands adjusted for age and sex, obesity $\left(\mathrm{BMI} \geq 30 \mathrm{~kg} / \mathrm{m}^{2}\right)$ doubled the risk of

Table 1 Maternal obesity and pregnancy outcome: a study of 287213 pregnancies in London, $U K^{\mathrm{a}}$

\begin{tabular}{lll}
\hline \multirow{2}{*}{ Parameter } & \multicolumn{2}{l}{ Relative risk (95\% CI) } \\
\cline { 2 - 3 } & BMI 25-29.9 & BMI $\geq 30$ \\
\hline Gestational diabetes & $1.68(1.53-1.84)$ & $3.60(3.25-3.98)$ \\
Proteinuric pre-eclampsia & $1.44(1.28-1.62)$ & $2.14(1.85-2.47)$ \\
Induction of labour & $2.14(1.85-2.47)$ & $1.70(1.64-1.76)$ \\
Delivery by emergency LSCS & $1.30(1.25-1.34)$ & $1.83(1.74-1.93)$ \\
Postpartum haemorrhage & $1.16(1.12-1.21)$ & $1.39(1.32-1.46)$ \\
Genital tract infection & $1.24(1.09-1.41)$ & $1.30(1.07-1.56)$ \\
Urinary tract infection & $1.17(1.04-1.33)$ & $1.39(1.18-1.63)$ \\
Wound infection & $1.27(1.09-1.48)$ & $2.24(1.91-2.64)$ \\
Birth weight>90th centile & $1.57(1.50-1.64)$ & $2.36(2.23-2.50)$ \\
Intrauterine death & $1.10(0.94-1.28)$ & $1.40(1.14-1.71)$ \\
Delivery before 32 weeks & $0.73(0.65-0.82)$ & $0.81(0.69-0.95)$ \\
Breast feeding at discharge & $0.86(0.84-0.88)$ & $0.58(0.56-0.60)$ \\
\hline
\end{tabular}

aData from Sebire et al. ${ }^{5}$

BMI, body mass index; CI, confidence interval; LSCS, lower segment Caesarean section. 
VTE. Obese individuals had higher levels of factor VIII and IX but not fibrinogen. Evaluation of the combined effect of COCs and obesity among women aged 15-45 years revealed that COCs further increased the effect of obesity on the risk of thrombosis, leading to a 10 -fold increased risk amongst women with a BMI> $25 \mathrm{~kg} / \mathrm{m}^{2} .14$

Guidance from the Clinical Effectiveness Unit states that after counselling, overweight women may choose to use a COC but consideration should be given to the use of alternative contraceptive methods. ${ }^{15}$ The British National Formulary recommends that women with a BMI $>39 \mathrm{~kg} / \mathrm{m}^{2}$ should not use $\mathrm{COC}^{16}$ and this seems to be standard practice in the UK. Very recent evidence suggests a much higher risk of VTE (four- to five-fold) in COC users when compared to data issued by the Committee on Safety of Medicines in 1995. No significant differences were observed between drospirenone-containing COCs, levonorgestrel-containing COCs and other formulations concerning cardiovascular events (i.e. VTE, myocardial infarction or stroke). ${ }^{17,18}$ These post-marketing data demonstrate the true prevalence of VTE in women taking COCs in the 21st century. With almost one in four women being obese, and in view of the recent data, safer prescribing is vital. Many 'experts' now suggest that in countries where there is a wide range of alternative contraceptive methods a BMI $>35 \mathrm{~kg} / \mathrm{m}^{2}$ absolutely contraindicates combined hormonal methods and advise caution when prescribing to women with a BMI $>30 \mathrm{~kg} / \mathrm{m}^{2}$. There are no data that suggest the combined hormonal patch behaves differently from a COC in this respect.

Does weight have an effect on the efficacy of COC? Most efficacy studies recruit women of normal body weight so an effect is unlikely to be seen.

A retrospective cohort study from Puget Sound in the USA has suggested that body weight may affect hormone metabolism sufficiently to compromise contraceptive efficacy in COC users. ${ }^{19}$ Analysis of data on 755 randomly selected women was performed with 618 women being ever-users of COCs. The authors state that during 2822 women-years of COC use the pregnancy rate was 3.8 per 100 women-years of exposure. After controlling for parity, women weighing $\geq 70.5 \mathrm{~kg}$ had a significantly increased risk of COC failure [relative risk (RR) 1.6, 95\% CI 1.1-2.4] compared to women of a lower body weight. Those in the highest weight quartile using low dose $(<50 \mu \mathrm{g}$ ethinylestradiol) and very low dose $(<35 \mu \mathrm{g}$ ethinylestradiol) pills had between a four- and five-fold increased risk of pregnancy. However, caution is needed in the interpretation of these results, as the heavier women may also have been less compliant pill takers. ${ }^{19}$

More recently studies comparing the combined hormonal patch with COCs included women who had a body weight up to $35 \%$ greater than normal. Contraceptive efficacy of the combined hormonal patch is similar to a COC. ${ }^{10}$ Results of pooled data from three studies comparing efficacy of the patch with different COCs showed that $5 / 15$ on-therapy pregnancies that occurred were in a subgroup of women with baseline body weight $\geq 90 \mathrm{~kg}$, which constituted $3 \%$ of the total study population..$^{20}$ The Summary of Product Characteristics for the patch suggests that it may be less effective in women weighing $>90 \mathrm{~kg} .{ }^{21}$

\section{Progestogen-only methods}

A continuing area of controversy relates to a possible increased failure of progestogen-only pills (POPs) in overweight women. This has recently been appraised ${ }^{22}$ and the author concluded that although there are no data showing that POPs are less effective in women weighing $>70 \mathrm{~kg}$, two POPs per day may be advised. A large cohort study failed to find an association between failure rates and body weight, height or BMI. However, it is possible the study was insufficiently powered to either prove or disprove this hypothesis. ${ }^{23}$ The recommendation is based on the fact that higher failure rates were seen in obese women using the levonorgestrel-releasing vaginal ring and in women $>70 \mathrm{~kg}$ using the older, hard tubing formulation of Norplant ${ }^{\circledR} .22$ However, changing to a softer tubing made the newer version of Norplant more effective in all women. ${ }^{24}$

There are no data to support the giving of two tablets of Cerazette ${ }^{\circledR}$ a day in women $>70 \mathrm{~kg}$. The main mechanism of action for this POP is inhibition of ovulation but it also has similar progestogenic effects to other POPs, producing secondary contraceptive effects in altering cervical mucus and endometrium. There are also no data to suggest that weight decreases the efficacy of Implanon ${ }^{\circledR}$ (data on file, Organon Laboratories Ltd), Depo-Provera ${ }^{\circledR 25}$ or the levonorgestrel intrauterine system (IUS). An initial study reported that serum etonogestrel levels were higher in women of lower body weight using Implanon. ${ }^{26}$ However, when studying the small number of reported failures with Implanon no association between body weight and efficacy has been found (data on file, Organon Laboratories Ltd) and it is therefore not necessary to replace Implanon earlier than the usual 3 years in heavier women.

No studies have reported a significant association with weight change in POP users. A randomised comparative trial comparing the levonorgestrel-releasing IUS and copper-containing intrauterine device failed to show an increase in weight with the IUS. ${ }^{27}$ Weight change in Implanon users has also been studied, with about $60 \%$ of women gaining at least $1 \mathrm{~kg}$ by 24 months and $37 \%$ gaining at least $3 \mathrm{~kg} .{ }^{28} \mathrm{~A}$ gradual increase in body weight over time has been shown in normal women of reproductive age so these findings may be only partly attributable to implant use and partly attributable to normal increases over time. For Depo-Provera users studies have shown that the mean weight gain after 1 year is usually about $2 \mathrm{~kg}$, rising to $9 \mathrm{~kg}$ with 5.5 years' use. ${ }^{29}$ It is thought that this is a result of increasing appetite in users, leading to deposition of fat. It is not related to fluid retention.

There are no data to suggest that obese women using progestogen-only contraceptive methods face an increased risk of adverse effects compared to other overweight women. Progestogen-only methods have not been shown to increase the risks of VTE or cardiovascular disease. 30,31

\section{Other methods}

There are no effects of weight on the efficacy or safety of barrier methods or fertility awareness methods. However, women who gain or lose more than half a stone in weight are advised to be remeasured for the diaphragm. Female sterilisation under general anaesthesia poses increased risks for obese women. Overweight people are more likely to suffer complications of general anaesthesia and their habitus increases the chance of a failed laparoscopic procedure necessitating a mini-laparotomy. New hysteroscopic techniques such as Essure ${ }^{\circledR}$, a minimally invasive, transcervically positioned micro-insert that occludes the Fallopian tubes, may offer advantages for such women. These micro-inserts can be inserted under hysteroscopic visualisation with intravenous sedation or paracervical block in over $85 \%$ of women.32 Further research is underway investigating their long-term safety and efficacy.

\section{Conclusion}

Much has been written in recent years about the global effects of diet, obesity and ill-health. As health 
professionals working in the field of contraception, we need to sit up and take note: advise about the importance of normalising BMI pre-pregnancy, endeavour to prescribe contraception safely, and offer alternatives when obesity contraindicates the use of COCs.

\section{Statements on funding and competing interests}

Funding. None identified.

Competing interests. The author has received financial support for lecturing, attending conferences and undertaking research for a number of pharmaceutical companies. She is also a member of advisory boards for a number of companies.

\section{Diana Mansour, FRCOG, MFFP}

Consultant in Community Gynaecology and Head of Service, Contraception and Sexual Health, Graingerville Clinic, Newcastle General Hospital, Westgate Road, Newcastle-upon-Tyne NE4 6BE, UK. E-mail: diana. mansour@newcastle-pct.nhs.uk

References

1 Vlad I. Obesity costs UK economy £2bn a year. BMJ 2003; 327 : 1308.

2 Bolumar F, Olsen J, Rebagliato M, et al. Body mass index and delayed conception; a European multicenter study on infertility an subfecundity. Am J Epidemiol 2000; 151: 1072-1079.

3 Castro LC, Avina RL. Maternal obesity and pregnancy outcomes. Curr Opin Obstet Gynecol 2002; 14: 601-606.

4 Rosenberg TJ, Garbers S, Chavkin W, et al. Pre-pregnancy weight and adverse perinatal outcomes in an ethnically diverse population. Obstet Gynecol 2003; 102: 1022-1027.

5 Sebire NJ, Jolly M, Harris JP, et al. Maternal obesity and pregnancy outcome: a study of 287,213 pregnancies in London. Int J Obes Relat Metab Disord 2001; 25: 1175-1182.

6 Lord JM, Flight IH, Norman RJ. Metformin in polycystic ovary syndrome: systematic review and meta-analysis. BMJ 2003; 327: 951-953.

7 Rodin DA, Bano G, Bland JM, et al. Polycystic ovaries and associated metabolic abnormalities in Indian subcontinent Asian women. Clin Endocrinol 1998; 49: 91-99.

8 Balen A. The current understanding of polycystic ovary syndrome. The Obstetrician and Gynaecologist 2004; 6: 66-74.

9 Gallo MF, Grimes DA, Schulz KF, et al. Combination contraceptives; effects on weight. Cochrane Database Syst Rev 2003; 2: CD003987.

10 Audet MC, Moreau M, Koltun MD, et al. Evaluation of contraceptive efficacy and cycle control of a transdermal contraceptive patch vs. an oral contraceptive. JAMA 2001; 285: 2347-2355

11 Farmer RDT, Lawrenson RA, Todd JC, et al. A comparison of the risks of venous thromboembolic disease in association with differen combined oral contraceptives. Br J Pharmacol 2000; 49: 580-590.

12 Lidegaard O, Erdstrom B, Kreiner S. Oral contraceptives and venous thromboembolism: a five-year national case-control study. Contraception 2002; 65: 187-196.

13 Jick H, Kaye JA, Vasilakis-Scaramozza C, et al. Risk of venous thromboembolism among users of third generation oral contraceptives compared with users of oral contraceptives with levonorgestrel before and after 1995: cohort and case-contro analysis. BMJ 2000; 321: 1190-1195.

14 Abdollahi M, Cushman M, Rosendaal FR. Obesity: risk of venous thrombosis and the interaction with coagulation factor levels and oral contraceptive use. Thromb Haemost 2003; 89: 493-498.

15 Faculty of Family Planning and Reproductive Health Care. Royal College of Obstetricians and Gynaecologists. First prescription of combined oral contraception: recommendations for clinical practice. Br J Fam Plann 2000; 26: 27-38.

16 British National Formulary, vol. 45. London, UK: British Medical Association and the Royal Pharmaceutical Society of Great Britain, March 2003

17 Pearce HM, Layton D, Wilton LV, et al. Reports of pulmonary embolism and deep vein thrombosis from a prescription event monitoring study of Yasmin TM in England. Pharmacoepidemiol Drug Saf 2004; 13: S256.

18 Heinemann LAJ, Assmann A, Lewis M, et al. The European Active Surveillance Study on Oral Contraceptives (EURAS-OC). Results after 50,000 WY of observation. Pharmacoepidemiol Drug Saf 2004; 13: S273-S274.

19 Holt VL, Cushing-Haugen KL, Daling JR. Body weight and risk of oral contraceptive failure. Obstet Gynecol 2002; 99: 820-827.

20 Zieman M, Guillebaud J, Weisberg E, et al. Contraceptive efficacy and cycle control with the Ortho Evra/Evra transdermal system: the analysis of pooled data. Fertil Steril 2002; 77(Suppl. 2): S13-S18.

21 Janssen-Cilag International NV. Evra transdermal patch. Summary of Product Characteristics. http://www.janssencilag.co.uk/product/ pdf/spc/00121.pdf.

22 de Souza A, Brechin S, Penney G. The members' enquiry service: frequently asked questions. J Fam Plann Reprod Health Care 2003; 29(3): 160-161.

23 Vessey M, Painter R. Oral contraception failures and body weight: findings in a large cohort study. J Fam Plann Reprod Health Care 2001; 27: 90-91.

24 Sivin I, Mishell DR, Darney P, et al. Levonorgestrel capsule implants in the United States: a 5-year study. Obstet Gynecol 1998; 92 $337-344$.

25 Jain J, Dutton C, Nicosia A, et al. Pharmacokinetics, ovulation suppression and return to ovulation following a lower dose subcutaneous formulation of Depo-Provera. Contraception 2004; 70 $11-18$

26 Huber J, Wenzl R. Pharmacokinetics of Implanon. An integrated analysis. Contraception 1998; 58: 85s-90s.

27 Andersson K, Odlind V, Rybo G. Levonorgestrel-releasing and copper-releasing (Nova T) IUDs during five years of use: randomized comparative trial. Contraception 1994; 49: 56-72.

28 Edwards JE, Moore A. Implanon: a review of clinical studies. $\mathrm{Br} \mathrm{J}$ Fam Plann 1999; 24(Suppl.): 3-16.

29 Bigrigg A, Evans M, Gbolade B, et al. Depo Provera. Position paper on clinical use, effectiveness and side effects. Br J Fam Plann 1999; 25: 69-76.

30 Heinemann LA, Assmann A, Do Minh T, et al. Oral progestogen-only contraceptives and cardiovascular risk: results from the Transnational Study on Oral Contraceptives and the Health of Young Women. Eur J Contracept Reprod Health Care 1999; 4: 67-73.

31 World Health Organization Collaborative Study of Cardiovascular Disease and Steroid Hormone Contraception. Cardiovascular disease and use of oral and injectable progestogen-only contraceptives and combined injectable contraceptives. Results of an international, multicenter, case-control study. Contraception 1998; 57: 315-324.

32 Kerin JF, Carignan CS, Cher D. The safety and effectiveness of a new hysteroscopic method for permanent birth control: results of the first Essure pbc clinical study. Aust N Z J Obstet Gynaecol 2001; 41 364-370.

\section{HOW TO REGISTER FOR ACCESS TO THE ELECTRONIC JOURNAL}

Registration Process

1. On connecting with the Faculty website (www.ffprhc.org.uk), click on the picture of the 'Journal' to access the electronic Journal.

2. Next, under Related Links, click on 'Faculty Membership Activation'.

3. In the appropriate boxes enter your Surname, E-mail Address, Country and Membership Number (M000, D000, etc six digits). NB. These boxes are case-sensitive.

4. Next, select a User Name and Password.

5. Ignore the box marked 'Ingenta Select ID number - CID'.

6. Click on 'Enable Access'

7. A confirmation e-mail will be sent to you.

\section{After Registration}

Once you have registered you can access the Journal as follows:

1. On connecting with the Faculty website (www.ffprhc.org.uk), click on the picture of the 'Journal' to access the electronic Journal.

2. Select the volume and issue number

3. Select the article you wish to view.

4. Enter your user name and password. 